\title{
GREAT DISCOUNTS ON AIRFARES!
}

Flying to New York for the 90th Annual Meeting, September 1 - 4? Call APSA's official travel agency, World Travel Partners, to obtain the following special discounts: $5 \%$ off any published fare, including discounted fares, and $10 \%$ off full coach unrestricted fares on Delta Airlines and USAir. Call early - seats are limited!

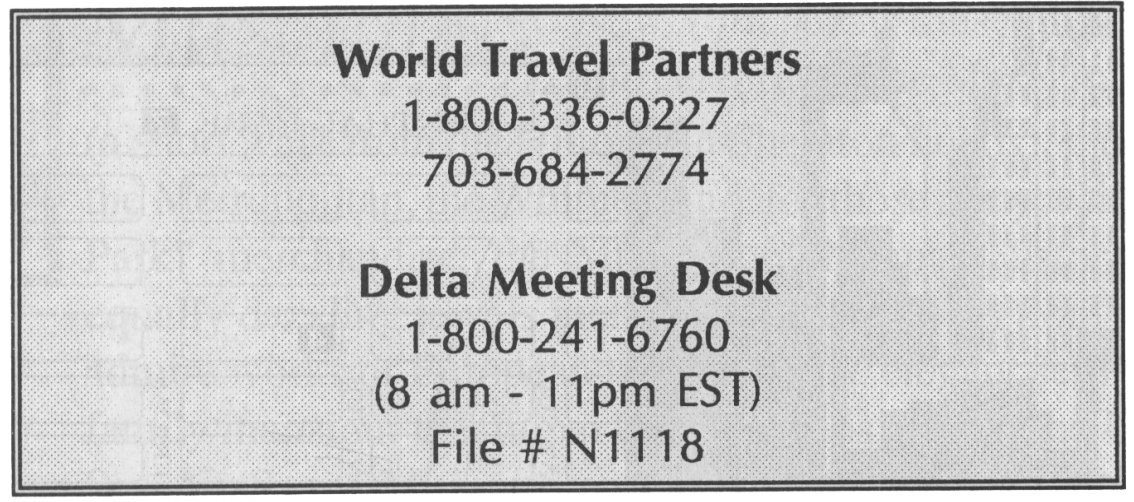

A.DELTAAIRLINES

YOU'LL LOVE THE WAY WE FLY. 